\title{
Akinesia in Parkinsonism. Relation between spontaneous movement (other than tremor) and voluntary movements made on command
}

\author{
CARL HA MEYER \\ From the Department of Neurosurgery, Royal Adelaide Hospital, South Australia
}

SUMmary In eleven patients with Parkinsonism there was a strong inverse relationship between the frequency of spontaneous activity of the arms and the degree of fatiguing of repetitive finger movements made upon command. The prevalence of spontaneous arm movement was related inversely (but more weakly) to the time taken to complete a pegboard test or to move clothespegs by hand; it had little association with the speed of linear movement or with simple motor reaction time involving the arm.

Various objective tests have been used to provide indices of the poverty of movement (commonly called akinesia) in patients with Parkinsonism. Tests used for this purpose have been concerned with the patients' slowness to initiate movement (as shown by tests of reaction time) ${ }^{1}$ with motor fatiguing (referring to the rapid decline in range, speed and power of movement when patients with Parkinson's disease try to sustain repetitive actions for an appreciable period), ${ }^{2}$ and with the patients' slowness to complete standardised motor tasks. ${ }^{3-7}$ Tests such as these involve movements that are predetermined and made in response to command. Do the results correspond with the relative immobility of such patients when they are left to their own devices (that is with the lack of spontaneous movement that is inherent in the clinical notion of akinesia $\left.{ }^{8-11}\right)$ ? The present study examines this question with respect to movements of the arm.

\section{Methods}

\section{Patients}

Eleven right-handed patients with idiopathic Parkinson's disease, two men and nine women, between 36 and 68 years of age (mean 57), were admitted to hospital during the late 1960's (before the introduction of amantadine, levodopa or related compounds) for stereotaxic surgical treatment of resting tremor or rigidity or both. All patients

Address for reprint requests: Dr Carl HA Meyer, The Midland Centre for Neurosurgery and Neurology, Holly Lane, Smethwick, Warley, West Midlands B67 7JX, UK

Received 25 April 1980 and in revised form 14 January 1982. Accepted 27 February 1982 were taking conventional doses of some form of anticholinergic medication though none had achieved substantial amelioration of their symptoms. All patients could stand up from a bed or chair without assistance and all could walk without support. None had any major disturbance of mental function evident on routine clinical examination.

\section{Programme of testing}

Clinical assessments were made of each patient's tremor, rigidity and motor fatiguing. On each of five consecutive days the patients performed standardised tests of voluntary movement and on each day they were assessed for the prevalence of their spontaneous actions.

Tremor, rigidity and motor fatiguing

These were assessed clinically (table 1). Motor fatiguing was evaluated while the patient actively opposed the four finger tips, one after another, to the thumb of the same hand. One series of oppositions followed another. Fatiguing was rated as the overall decline in speed and amplitude that occurred despite the patient's efforts to sustain the activity.

\section{Standardised tasks of voluntary movement}

(a) Placing clothespegs on line: six wooden clothespegs, each activated by a metal spring, were clipped to the edge of a thin board fixed.at the level of the subject's waist. The time was taken for him to place all six, one by one, on a clothesline held level with his eyes. On each day of testing he made three scoring runs with the right hand (moving six pegs for each run). The times for the three runs were added together to determine his rating for that day. A similar procedure was followed for the left hand.

(b) pegboard test: the time was taken for the patient's right hand to move 35 cylindrical metal pegs in a predetermined order from holes in the left half of the pegboard to a corresponding set of vacant holes in the right 
Table 1 Scores for Individual Subjects (1) Clinical Estimates ( $T=$ resting tremor (severity assessed for arm as a whole), $R$ $=$ muscular rigidity (severity for arm as a whole), $M F=$ motor fatiguing; see text, Methods.) For a given limb, three equally skilled observers rated each of $T, R$ and $M F$ on a scale with interval points: 0 (normal), 1 (mild involvement), 2 (moderate involvement), and 3 (marked involvement). The scores of the three observers are added together so that for a given limb the possible scores for each of $T, R$ and $M F$ range between $O$ and 9. (2) Standardised tasks: For tests with clothespegs, pegboard and drawing board (reaction time and transit time, $T b$ ) scores are given for Day 5. (3) Spontaneous movement (SM = Number of spontaneous actions on Days 2-5 inclusive):

\begin{tabular}{|c|c|c|c|c|c|c|c|c|c|}
\hline & \multirow[t]{3}{*}{ Patient } & \multicolumn{3}{|c|}{ Clinical estimates } & \multicolumn{4}{|c|}{ Standardised tests } & \multirow{3}{*}{$\begin{array}{l}\begin{array}{l}\text { Spontaneous } \\
\text { movement }\end{array} \\
\text { SM (Number) }\end{array}$} \\
\hline & & \multirow[t]{2}{*}{$T$} & \multirow[t]{2}{*}{$R$} & \multirow[t]{2}{*}{$M F$} & \multirow[t]{2}{*}{ Clothespegs (s) } & \multirow[t]{2}{*}{ Pegboard (s) } & \multicolumn{2}{|c|}{ Drawing test } & \\
\hline & & & & & & & $\begin{array}{l}\text { Reaction } \\
\text { time }(s)\end{array}$ & $\begin{array}{l}\text { Transit } \\
\text { time }(T b)(s)\end{array}$ & \\
\hline Right arm & $\begin{array}{l}\text { A } \\
\mathbf{B} \\
\text { C } \\
\mathbf{D} \\
\mathbf{E} \\
\mathbf{F} \\
\mathbf{G} \\
\mathbf{H} \\
\mathbf{I} \\
\mathbf{J} \\
\mathbf{K}\end{array}$ & $\begin{array}{l}0 \\
0 \\
1 / 2 \\
3 \\
6 \\
0 \\
0 \\
0 \\
3 \\
4 \\
6\end{array}$ & $\begin{array}{l}3 \\
4 \\
81 / 2 \\
2 \\
3 \\
0 \\
1 \\
0 \\
8 \\
7 \\
3\end{array}$ & $\begin{array}{l}3 \\
4 \\
8 \\
0 \\
11 / 2 \\
2 \\
0 \\
3 \\
7 \\
8 \\
3\end{array}$ & $\begin{array}{r}23.5 \\
38.0 \\
73.0 \\
31.0 \\
38.5 \\
33.5 \\
51 \cdot 5 \\
30.5 \\
33.5 \\
102.0 \\
38.0\end{array}$ & $\begin{array}{l}43.0 \\
57.5 \\
72.0 \\
53.5 \\
52.0 \\
53.0 \\
73.5 \\
55.0 \\
54.0 \\
93.5 \\
63.5\end{array}$ & $\begin{array}{l}1.49 \\
1.61 \\
1.92 \\
1.77 \\
2.04 \\
1.90 \\
1.94 \\
1.65 \\
2.14 \\
2.08 \\
1.66\end{array}$ & $\begin{array}{l}1 \cdot 29 \\
1 \cdot 19 \\
2 \cdot 12 \\
1.76 \\
1.44 \\
1.52 \\
8.24 \\
1.60 \\
2.23 \\
4.82 \\
1.65\end{array}$ & $\begin{array}{r}310 \\
179 \\
20 \\
227 \\
555 \\
722 \\
318 \\
198 \\
121 \\
52 \\
159\end{array}$ \\
\hline Left arm & $\begin{array}{l}\text { A } \\
\text { B } \\
\text { C } \\
D \\
\text { E } \\
\text { F } \\
\text { G } \\
\text { H } \\
\text { I } \\
\text { J } \\
\mathbf{K}\end{array}$ & $\begin{array}{l}41 / 2 \\
9 \\
1 \\
6 \\
6 \\
5 \\
0 \\
7 \\
1 / 2 \\
0 \\
0\end{array}$ & $\begin{array}{l}9 \\
8 \\
81 / 2 \\
51 / 2 \\
21 / 2 \\
4 \\
7 \\
3 \\
4 \\
11 / 2 \\
1 / 2\end{array}$ & $\begin{array}{l}8 \\
6 \\
9 \\
6 \\
11 / 2 \\
6 \\
6 \\
5 \\
3 \\
3 \\
0\end{array}$ & $\begin{array}{l}31 \cdot 5 \\
42.0 \\
73 \cdot 0 \\
43.5 \\
41.5 \\
59.5 \\
56 \cdot 5 \\
47 \cdot 0 \\
32 \cdot 5 \\
46.5 \\
39.5\end{array}$ & $\begin{array}{l}61.0 \\
78.0 \\
91.0 \\
72.5 \\
52.5 \\
86.5 \\
77.5 \\
69.5 \\
53.0 \\
66.0 \\
71.0\end{array}$ & $\begin{array}{l}1.73 \\
1.84 \\
2.36 \\
2.44 \\
2.03 \\
2.08 \\
2.10 \\
1.95 \\
1.93 \\
2.08 \\
1.64\end{array}$ & $\begin{array}{l}1 \cdot 91 \\
1 \cdot 16 \\
1 \cdot 90 \\
2.02 \\
1.22 \\
1 \cdot 77 \\
8 \cdot 17 \\
1.46 \\
1 \cdot 81 \\
3.12 \\
1.37\end{array}$ & $\begin{array}{r}100 \\
105 \\
11 \\
120 \\
406 \\
176 \\
166 \\
176 \\
278 \\
311 \\
290\end{array}$ \\
\hline
\end{tabular}

half. For the left hand, the time was taken for the subject to move the pegs from the right side of the board to the left.

(c) Drawing board test: 1 Motor reaction time, 2 Slowness of linear movement $(\mathrm{Tb})$. In response to a lamp activated by an examiner the subject used a metal stylus to draw freehand as quickly as possible from one side of a special drawing board to the other. The stylus swept successively across three surface areas, one $21 \mathrm{~cm}$ wide, the next $41 \mathrm{~cm}$ wide, and the third $20 \mathrm{~cm}$ in width. When the right hand was used the stylus traversed these surfaces in order passing from left to right. When the left hand was used the board was turned about so that the stylus crossed the same surfaces in the same order but in a direction from right to left. An estimate of simple reaction time was provided by the time taken for the stylus to begin moving after the cue lamp had been activated. The time taken for it to get from one side to the other of the middle surface area $(41 \mathrm{~cm}$ wide) provided a simple index ( $\mathrm{Tb}$ ) of the patient's slowness for linear movement. The demand for speed meant that the stylus tended to describe a course that was slightly curved with the convexity directed away from the person drawing, but any difference among patients with respect to the distance travelled by the stylus was unimportant in relation to the magnitude of the time interval being measured. On each day of testing the subject made six scoring runs. Values for the reaction time and for transit ( $\mathrm{Tb}$ ) were decided for each traverse of the stylus. For each hand the total score for each parameter was determined by adding the appropriate six values together.
Spontaneous movement: On each of the five days of testing the patient first performed with the clothespegs and with the pegboard, then an assessment was made of spontaneous movement, and finally the subjects performed the test using the drawing board. At the appropriate time in the daily schedule the subject was left alone sitting on a chair in a room with fittings and furnishings that were appropriate to the hospital setting. Its arrangement and lighting were kept constant from day to day. The level of background noise was constant and moderate in degree. Unbeknown to him the subject was watched for ten minutes through a one-way mirror. Note was made of the number of actions (apart from tremor) that he made with each arm during this period. The actions had sufficient amplitude to make them apparent to clinical inspection. For each arm the prevalence of spontaneous movement (SM) was determined by adding together the number of actions for the second to the fifth days inclusive.

\section{Statistical methods}

Statistical tests are performed as described by Siegel. ${ }^{12}$ Two-tailed tests are used throughout.

\section{Results}

Studies with normal subjects of approximately the same age as the current patients indicated that sex did not exert a substantial influence on the perfor- 
mance with clothespegs, with the pegboard, or with the drawing board (whether for reaction time or for the parameter $\mathrm{Tb}$ ). In the present study male and female Parkinsonian patients are taken together as a single group.

Between the first and fifth days of testing there was no convincing change in the patients' scores with either hand for moving the clothespegs or for the slowness of linear movement (parameter $\mathrm{Tb}$ of the test with the drawing board). During this interval there was some improvement with either hand for the pegboard test and for motor reaction time ( $p$ $<0.05$ or better, Wilcoxon test): however for these estimates there was no convincing difference between the scores on the fourth and fifth days of testing. Thus the patients' performance had become reasonably stable by the fifth day-and the scores for this day constitute the best available estimate of the subjects' performance of each standardised task.

Table 1 summarises each patient's scores for tremor, rigidity and motor fatiguing, for the timed performance (on Day 5) of the standardised tasks of voluntary movement, and for the prevalence of spontaneous movement (on Days 2-5).

As shown by table 2 the prevalence of spontaneous movement was inversely related to the degree of muscular rigidity, to the degree of motor fatiguing and, very weakly, to the time taken to complete the pegboard test. From table 3 it appears that the association between spontaneous movement and motor fatiguing does not depend solely on the relationship that each bears to rigidity. This is also true for the association between spontaneous movement and the performance of the pegboard test.

\section{Discussion}

In the present study of arm movements in patients with Parkinson's disease there was no close correlation between the prevalence of spontaneous motor behaviour and the patients' performance of tests involving pegboard, clothespegs or drawing board in which voluntary movements were made in response to command. Tests such as these do not, therefore, provide a good clinical index of akinesia in the sense that akinesia implies poverty of spontaneous motor behaviour.

The current results accord with the view ${ }^{3} 1314$ that the proficiency of the patient with Parkinson's disease for one type of movement is no safe prediction of his performance of movements that are sufficiently different in nature. It is noteworthy that the results do not support the view ${ }^{1}$ that tests of reaction time are a good measure of the spontaneity of movement in Parkinsonism. The motor behaviours involved in reaction time and spontane-
Table 2 Correlation between spontaneous movement and other parameters of motor function

\begin{tabular}{lll}
\hline $\begin{array}{l}\text { Correlation between } \\
\text { spontaneous movement } \\
\text { and: }\end{array}$ & $\begin{array}{l}\text { Right arm } \\
r_{s}\end{array}$ & $\begin{array}{l}\text { Left arm } \\
r_{s}\end{array}$ \\
\hline $\begin{array}{ll}\text { Tremor } \\
\text { Rigidity }\end{array}$ & -0.25 & -0.02 \\
Motor fatigue & $-0.76 \dagger$ & $-0.92 \S$ \\
Clothespegs & $-0.82 \ddagger$ & $-0.88 \ddagger$ \\
$\begin{array}{l}\text { Pegboard } \\
\text { Drawing test }\end{array}$ & -0.36 & -0.23 \\
$\quad$ Reaction time & $-0.62^{*}$ & $-0.59^{*}$ \\
$\quad$ & -0.19 & -0.18 \\
Transit time (Tb) & -0.40 & -0.21 \\
\hline
\end{tabular}

Correlations expressed as Spearman coefficient of correlation $\left(r_{r}\right)$. Significance (two-tailed test): ${ }^{*} p<0.10 ; \dagger p<0.02 ; \neq p<0.01 ; \$ p<0.001$

Table 3 Association between parameters (with rigidity eliminated)

\begin{tabular}{lllll}
\hline $\begin{array}{l}\text { Correlation } \\
\text { between } \\
\text { spontaneous } \\
\begin{array}{l}\text { movement } \\
\text { and: }\end{array}\end{array}$ & \begin{tabular}{l} 
Right arm \\
\cline { 2 - 5 }
\end{tabular} & $\begin{array}{l}\tau \\
\text { (With rigidity } \\
\text { partialled } \\
\text { out) }\end{array}$ & $\begin{array}{l}\tau \\
\text { (With rigidity } \\
\text { partialled } \\
\text { out) }\end{array}$ \\
\hline $\begin{array}{llll}\text { Motor fatigue } \\
\text { Pegboard }\end{array}$ & -0.73 & -0.57 & -0.76 & -0.47 \\
\hline
\end{tabular}

Associations expressed as Kendall coefficient of correlation $(\tau)$ and also as Kendall rank partial coefficient (with the influence of rigidity eliminated)

ous movement may well be influenced by factors in common (such as the patient's level of alertness, his readiness to respond to visual stimuli, and any rigidity opposing the initiation of movement), however the two assessments were performed in circumstances that differ in important respects. Reaction time was tested with the patient ready to respond to a predetermined stimulus with a stereotyped response. During the assessment of spontaneous movement, however, the patient's actions were made without instruction or constraint and were more open to influence from factors such as his own initiative or his readiness to respond to background stimuli.

The strong association found here between the fatiguing of repetitive finger movements and the poverty of spontaneous actions of the arm supports the view ${ }^{2}$ that fatiguing of voluntary movement is an especially useful index of motor behaviour in patients with Parkinsonism. Although the current patients all had some degree of rigidity in their arms it appears that the association between motor fatiguing and the poverty of spontaneous movement does not arise solely from their mutual association with rigidity. To confirm this would require further study involving Parkinsonian patients with appreciable poverty of movement but relatively little rigidity. A factor common to motor fatiguing and the loss of spontaneous movement may well be the decrease in 
the Parkinsonians' activation of behaviour, ${ }^{15} 16$ a change that has been linked with reduction in monoaminergic transmission within the brainstem and basal ganglia. ${ }^{16-23}$

Despite the fact that akinesia, bradykinesia and hypokinesia are used freely to refer to the poverty of movement in patients with Parkinson's disease, there is no agreement concerning the precise definition of these terms. It would seem useful to have them denote the impairment of separate elements of motor behaviour, ${ }^{24}{ }^{25}$ particularly since the change that Parkinson's disease brings to one element (such as the initiation of spontaneous actions) may be poorly related to the change in other elements (such as the velocity of movementrepresented in the present work by the transit time, $\mathrm{Tb}$, for the drawing-board test). "Akinesia" could well refer to the failure of movements to begin (that is to the reduced number of separate actions made spontaneously in a certain time). "Bradykinesia" could then denote the slowness of movement (referring to the speed of linear movement as observed clinically), while "hypokinesia" could signify reduction in the amplitude of movement.

I thank Mr TAR Dinning, Mr DA Simpson and Mr HR Schaeffer for allowing me to report on patients admitted under their care to Royal Adelaide Hospital. I am also grateful to the Neurosurgical Research Foundation of South Australia Inc for supporting the study and to $\mathrm{Mr} \mathrm{PH}$ Schurr and Dr David Parkes for advice during the preparation of this paper.

\section{References}

' Barbeau A. The problem of measurement of akinesia. $J$ Neurosurg 1966;24 (suppl):331-4.

${ }^{2}$ Schwab RS, England AC Jr, Peterson E. Akinesia in Parkinson's disease. Neurology (Minneap) 1959;9:65-72.

${ }^{3}$ Brumlik J, Boshes B. The mechanism of bradykinesia in parkinsonism. Neurology (Minneap) 1966;16:337-44.

4 Webster DD. Critical analysis of the disability in Parkinson's disease. Med Treat 1968;5:257-82.

${ }^{5}$ Godwin-Austen RB, Tomlinson EB, Frears CC, Kok HWL. Effects of L-dopa in Parkinson's disease. Lancet 1969;2:165-8.
- Parkes JD, Baxter RCH, Curzon G et al. Treatment of Parkinson's disease with amantadine and laevodopa. Lancet 1971; 1:1083-7.

7 Van Buren JM, Li C-L, Shapiro DY, Henderson WG, Sadowsky DA. A qualitative and quantitative evaluation of parkinsonians three to six years following thalamotomy. Confin Neurol 1973;35:202-35.

${ }^{8}$ Alba A, Trainor FS, Ritter W, Dacso MM. A clinical disability rating for parkinson patients. $J$ Chron Dis 1968;21:507-22.

9 Angel RA, Alston W, Higgins JR. Control of movement in Parkinson's disease. Brain 1970;93:1-15.

${ }^{10}$ Flowers KA. Visual "closed-loop" and "open-loop" characteristics of voluntary movement in patients with parkinsonism and intention tremor. Brain 1976; 99:269-310.

"Flowers K. Lack of prediction in the motor behaviour of parkinsonism. Brain 1978; 101:35-52.

${ }^{12}$ Siegel S. Nonparametric statistics for the behavioural sciences. Tokyo: Kōhakusha, McGraw-Hill, 1956.

13 Talland GA. Manual skill in Parkinson's disease. J Nerv Ment Dis 1963;135:193-205.

${ }^{14}$ Cassell K, Shaw K, Stern G. A computerized tracking technique for the assessment of parkinsonian motor disabilities. Brain 1973;96:815-26.

${ }^{15}$ Duffy E. An explanation of "emotional" phenomena without the use of the concept "emotion". J Gen Psychol 1941;25:283-93.

${ }^{16}$ Riklan M, Levita E. Subcortical correlates of human behaviour. Baltimore: Williams \& Wilkins, 1969.

${ }^{17}$ Riklan M. Laevodopa and behaviour. Neurology (Minneap) 1972; 22 (suppl):43-54.

${ }^{18}$ Horvath TB, Meares RA. L-dopa and arousal. J Neurol Neurosurg Psychiatry 1974; 37:416-21.

${ }^{19}$ Lindsley DF, Ranf SK, Fernandez FC, Wyrwicka W. Effects of anti-parkinsonian drugs on the motor activity of EEG of cats with subthalamic lesions. Exp Neurol 1975; 47:404-18.

${ }^{20}$ Poirier LJ, Filion M, Larochelle L, Péchadre J-C. Physiopathology of experimental parkinsonism in the monkey. Can J Neurol Sci 1975; 2:255-63.

${ }^{21}$ Péchadre J-C, Larochelle L, Poirier LJ. Parkinsonian akinesia, rigidity and tremor in the monkey. $J$ Neurol Sci 1976; 28:147-57.

${ }^{22}$ Péchadre J-C. Extra neo-striatal dopaminergic activity and akinesia. Can J Neurol Sci 1979; 6:87.

${ }^{23}$ Anden N-E. The significance of the neostriatum and the nucleus accumbens for the rigidity and akinesia induced by neuroleptic drugs. Can J Neurol Sci 1979; 6:73.

${ }^{24}$ Schneider P. Quantitative Analyse und Mechanismen der Bradykinesie bei Parkinsonpatienten. Dtsch Z Nervheilk 1968; 194:89-102.

${ }^{25}$ DeJong JD, Jones GM. Akinesia, hypokinesia and bradykinesia in the oculomotor system of patients with Parkinson's disease. Exp Neürol 1971; 32:58-68. 